patient was first examined by me, a large, raised, vascular boss, not tender, was present in the upper and inner quadrant of the sclera, in contact with the edge of the cornea. Eleven weeks later the nodule had disappeared, leaving a slight discolouration at its site. At a later period a specific history was obtained, and the Wassermann reaction was found to be positive.

Case No. 2.-A female, aged 36, was seen two months after herpes zoster on the right side of the head, with eye complications coming on a few days later. The right side of the patient's forehead was covered with post-herpetic scars; the cornea, the sensibility of which was somewhat diminished, presented the scars of an herpetic eruption, and there were two swellings, each about the size of a large split pea, in the lower half of the sclera. About one month later one of the swellings had almost disappeared, and the other was smaller.

Case No. 3.-A male, aged 66, had an attack of severe herpes on the right side, and fourteen days later cutaneous red patches in relation to the branches of the first division of the fifth nerve, including the nasal branch. The skin and the cornea were painful and tender. The lower half of the last-named was cloudy from keratitis striata and "keratitis punctata." The iris was injected. There were three reddish swellings on the sclera. All the conditions made a satisfactory, although rather slow, recovery. During the course of treatment the hypertrophied middle turbinal bodies were treated with the electric cautery.

Case No. 4.-A female, aged 57, suffered from intense pain down the left side of the nose and forehead, radiating into the left ear and back of neck; had many small red areas on the skin of the left frontal region, and oedema of the inner end of the left upper eyelid, and a large patch of conjunctival injection on the nasal side of the cornea. A week later she developed vesicles along the branches of the first division of the fifth nerve, including the nasal branch. Five months later the cornea presented three opacities (healed vesicles), and there were two small, raised, rounded, reddish patches with discoloured centres on the nasal side of the sclera, not far from the edge of the cornea. Ten months later there was only a slight discolouration of the sclera near the cornea.

\title{
ANNOTATIONS
}

\section{Opticians and National Service}

A case which is of considerable interest to medical men in general and to ophthalmic surgeons in particular, has been recently argued before the Appeal Tribunal in Jersey. A local paper reports the hearing 
at full length, heading the account "Opticians versus Ophthalmic Surgeons." The military representative based his opposition to exemption chiefly on the ground that the optician was not employed on work of public importance, but engaged in work that was prejudicial and even detrimental to the public interest. $\mathrm{He}$ read a letter in support of his case from the Central Medical War Committee. The advocate on the other side, who was inclined to be abusive, and hinted that the appeal was a "put up job" of a certain ophthalmic surgeon in practice in the island, produced a letter from the Ministry of National Service, in which it was stated that it had been decided to include sight-testing opticians in the list of certified occupations, and that instructions had been issued that, pending its publication, a man of the new military age was not to be called up even for medical examination, provided that he was engaged in the occupation named below, on or after August 15, 1915. Opticians (sight-testing). "Men who have passed the examination of the Spectacle Makers' Company or of the British Optical Association, and have been regularly and habitually employed or engaged as sight-testing opticians for more than ten years."

The result of the case was that the military appeal was dismissed and the Court declined to hear the medical men concerned or even to allow them to answer the allegations made against them.

Without going into the question of whether sight-testing opticians do more harm than good, there are two points that strike us as worthy of notice :

(1) It would seem to be the sight-testing optician who is so especially favoured. The man who confines himself to his legitimate business of fitting up spectacles to prescriptions, and has not passed the examination of certain trade associations and companies, is apparently not exempt.

(2) Whatever age the man may be, if he has been regularly engaged in his business for ten years, he is exempt from being even called up for medical examination. This, contrasted with the case of the medical man, who is liab'le up to the age of 55 , not only to be called up for medical examination, but possibly taken away from his practice which he may have carried on regularly for thirty years, is interesting. The position can only be described as grossly unjust.

\section{The Development of the Optician}

von Rohr has recently (Klin.Monatsbl. f. Augenheilk., Nov.-Dec., 1917) traced the development of the optician in Germany. Before the nineteenth century there was no friction in that country between medical man and optician who kept a small shop and 